\title{
FRICTION COEFFICIENT DETERMINATION BASED ON THE RESULTS OF BALL-ON-FLAT TEST
}

\author{
Elżbieta Szymczyk, Jerzy Jachimowicz, Lukasz Prasek \\ Military University of Technology \\ Department of Mechanics and Applied Computer Science \\ Gen. Sylwestra Kaliskiego Street 2, 00-908 Warsaw, Poland \\ tel.: +4822 6839039, fax: +48226839355 \\ e-mail:eszymczyk@wat.edu.pl
}

Anna Piątkowska

Institute of Electronic Materials Technology

133 Wólczyńska Street 133, 01-919 Warsaw, Poland

\begin{abstract}
The interaction of contacting surfaces in relative motion is basic for every engineering design. The transmission of load from one rubbing surface to its mating surface under conditions of dry contact is taken into account. Microlocal or global models of friction are used to describe this phenomenon. In global approach, frictional force is proportional to normal load. A coefficient of external friction depends on the type, shape, and precision of finishing the surfaces of mating elements.

The aim of the paper is analysis of a friction coefficient for $2024 T 3$ aluminium alloy during cyclic tangential loading. Experimental tests are carried out on a ball-on-flat wear-testing machine Ducom. Tests of reciprocating friction are carried out using the following friction pairs of specimens: the ball specimen is made of high strength aluminium alloy PA25 and the plane specimen is made of $2024 T 3$ alloy. Finally, graphs of temporary friction coefficients versus time in the form of fluctuated periodical functions are obtained. Two phases of friction are detected. However, during the first stage, the friction coefficient is relatively small while in the second period it rapidly increases and tends to become more irregular. Static and dynamic friction coefficients are estimated. In order to determine the dynamic coefficient the Discrete Fourier Transformation is used. The calculation of the dominant amplitude (corresponding to test frequency) of the studied functions is possible due to this method.

An increase of the friction coefficient with an increase of normal load is observed. A cladding layer also causes an increase of friction, especially in the second phase.
\end{abstract}

Keywords: friction coefficient, ball-on-flat test, FFT

\section{Introduction}

The interaction of contacting surfaces in relative motion is basic for every engineering design [1]. The transmission of load from one rubbing surface to its mating surface under conditions of dry contact is taken into account, especially in riveted or bolted joints. Friction properties of the given material are not its intrinsic properties, but depend on many factors related to its specific application: relevant properties of mating components, mutual interaction of the components as well as environment humidity, temperature and pollution [2]. Fretting is recognised as a surface damage phenomenon and describes situation where microslip between contacting surfaces appears to give rise to reduction in fatigue life. Fretting depends on the following reasons: surface smoothness, hardness of mating elements, magnitude of normal and tangential forces and relative displacement amplitude and frequency [3]. Stress concentrations and effects such as surface damage (fretting wear) are unfavourable since they tend to the fatigue crack initiation [4]. Besides, mechanical as well as electrochemical phenomena (i.e. corrosion) occur between components, however, they are not considered in the paper. 
Microlocal or global models of friction are used to describe this phenomenon [5]. In global approach (applied in structural analysis), frictional force is proportional to normal load. Determination of friction force for aluminium alloy 2024T3 is presented i.e. in paper [6]. Test arrangement and the results are presented in Fig. 1. The friction coefficient is changed from 0.23 to 0.12 with an increase in normal pressure from $10 \mathrm{MPa}$ do $70 \mathrm{MPa}$.

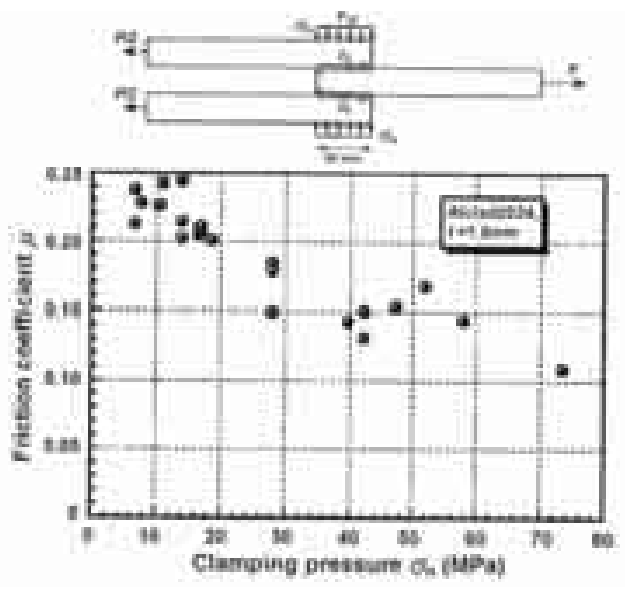

Fig. 1. Friction coefficient [6]

A coefficient of external friction depends on the type, shape, and precision of finishing the surfaces of mating elements. In general, the transmission of load is associated with concentration of the contact pressure. Contact will confine itself mainly close to the summits of the highest asperities. Therefore, the areas of real contact tend to be dispersed over the Hertzian area [2, 7].

Estimation of the friction coefficient during a wear test is presented e.g. in paper [7]. The coefficient value obtained at the beginning of the test is about 0.15 , however, after a few thousand cycles, due to accumulation of wear debris, a rapid growth of the friction coefficient to 0.65 occurred.

The aim of the paper is analysis of a friction coefficient for $2024 \mathrm{~T} 3$ aluminium alloy during cyclic tangential loading.

\section{Experimental study}

Wear tests are carried out on a ball-on-flat wear-testing machine Ducom in ITME. The tests of reciprocating friction are carried out using the following friction pairs of specimens.

The ball specimen is made of high strength aluminium alloy PA25 used as rivet material. The Brinell hardness number is about 115 and Young's modulus is $70 \mathrm{GPa}$. The spherical contact surface (radius $4 \mathrm{~mm}$ ) of the ball specimen is finished by grinding and its surface roughness $\mathrm{R}_{\mathrm{a}}$ (means average asperity height) before the wear test is about $0.08 \mu \mathrm{m}$.

The plane specimen $(20 \times 20 \times 1.2 \mathrm{~mm})$ is made of 2024T3 aluminium alloy, which is commonly used in aircraft structures. The Brinell hardness number for the bar specimen is about 115 however for pure aluminium used in a cladded specimen it is only 15. Young modulus is $68 \mathrm{GPa}$. The contact surface of the flat specimens is finished by rolling (case c1) and cladding (case c2) and their surface roughness $R_{a}$ before the wear test is about $0.2-0.3 \mu \mathrm{m}$. Thickness of a cladded layer is $30 \mu \mathrm{m}$ (Fig. 2).

The ball-shaped upper specimen slides against the lower flat specimen (Fig. 3). These specimens move relative to one another in a linear, forward, and backward sliding motion (one cycle) without lubrication, under a prescribed set of conditions. In this test method, the load is applied vertically downward through the ball specimen against the horizontally mounted flat specimen. The normal load $N$ and corresponding contact stress (according to Hertzian theory), stroke length, frequency of oscillation, test temperature and sliding distance are presented in Tab. 1. 


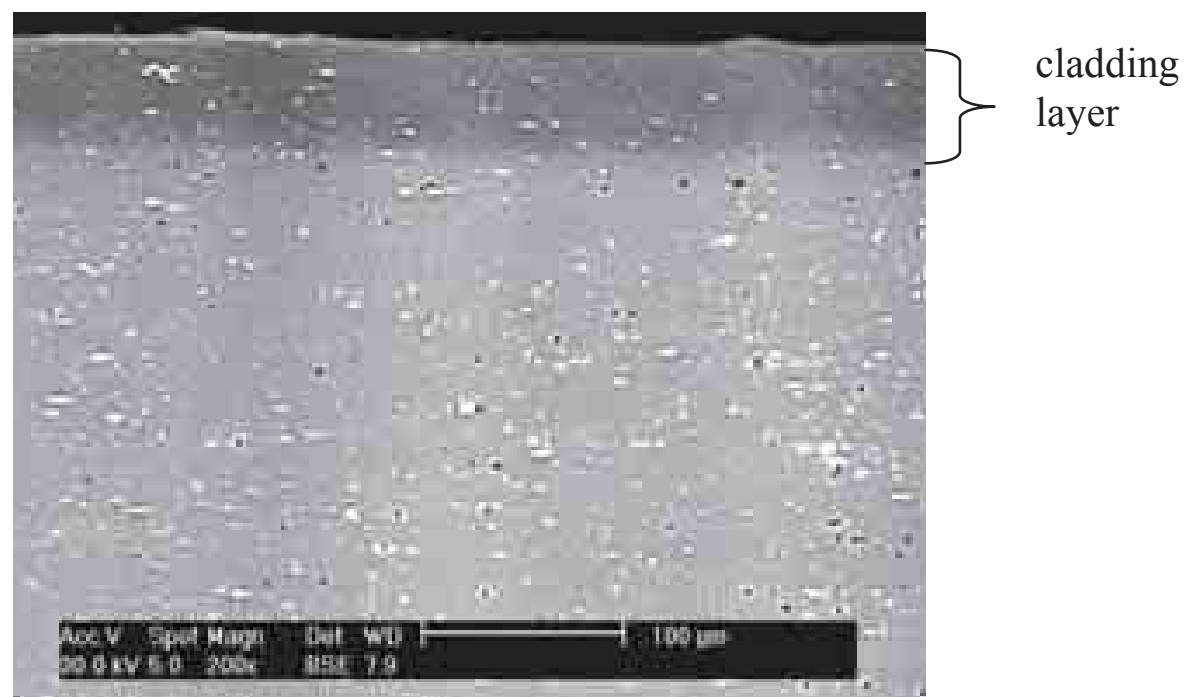

Fig. 2. Cladding $2024 T 3$ specimen

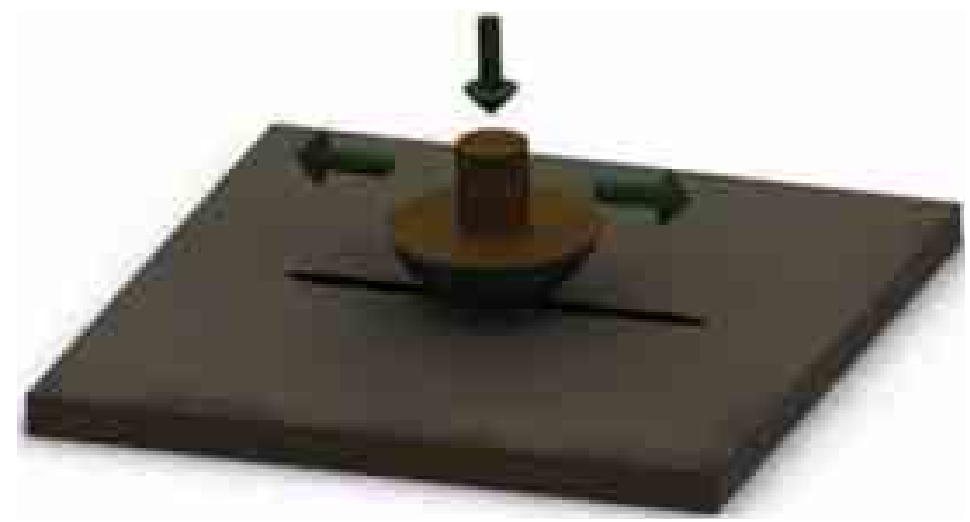

Fig. 3. Friction pair of specimens

Tab. 1. Test parameters

\begin{tabular}{|c|c|c|c|c|c|c|c|}
\hline \multirow{2}{*}{ No. } & \multirow{2}{*}{ temperature } & \multirow{2}{*}{$\begin{array}{c}\text { stroke } \\
\text { length }[\mathrm{mm}]\end{array}$} & \multirow{2}{*}{$\begin{array}{c}\text { frequency } \\
\qquad[\mathrm{Hz}]\end{array}$} & \multirow{2}{*}{$\begin{array}{c}\text { sliding } \\
\text { distance }[\mathrm{mm}]\end{array}$} & \multirow{2}{*}{$\begin{array}{l}\text { applied } \\
\text { load [N] }\end{array}$} & \multicolumn{2}{|c|}{ contact stress $[\mathrm{MPa}]$} \\
\hline & & & & & & maximum & average \\
\hline 1 & \multirow{3}{*}{ ambient } & \multirow{3}{*}{10} & \multirow{3}{*}{1} & \multirow{3}{*}{600} & 5 & 455 & 303 \\
\hline 2 & & & & & 10 & 574 & 382 \\
\hline 3 & & & & & 15 & 657 & 438 \\
\hline
\end{tabular}

Frictional (resistance) force $T_{j k}$ is recoded during the test with frequency $26.5 \mathrm{~Hz}$ (26-27 points per one cycle) and temporary friction coefficient $\mu_{j k}$ is calculated as follows

$$
\mu_{j k}=\frac{T_{j k}}{N},
$$

where:

$N$ - normal load,

$T_{j k}$ - frictional force,

$j-$ point number in the cycle,

$k-$ cycle number.

Wear profiles are analysed using SEM (Fig. 4). Width of wear tracks depend on applied load and surface coating (bar - case $\mathrm{c} 1$ and cladded - case c2). Maximum values of track width for specified load are compared in Fig. 4. 

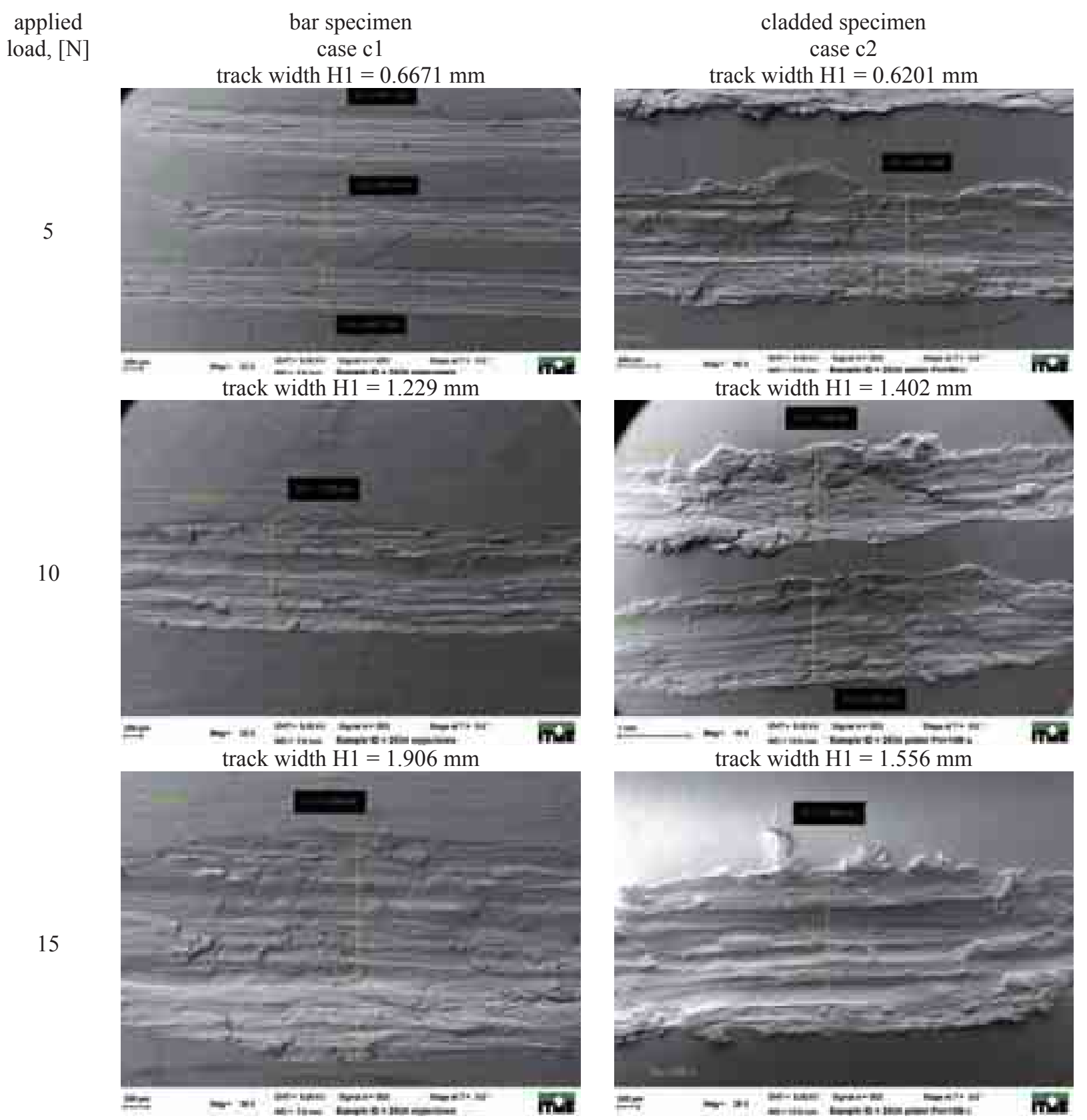

Fig. 4. Wear profiles for $2024 T 3$ aluminium alloy specimens

A typical graph of the friction coefficient versus time in the form of fluctuated periodical functions is presented in Fig. 5. Positive and negative values of temporary friction coefficient corresponded to forward and backward sliding direction. Two phases of friction are exposed in Fig. 5a. However, during the first stage (Fig. 5b) the friction coefficient is relatively small while in the second period it rapidly increases and tends to become more irregular. Similar results are presented in papers [Metals Hanbook vol. 18, Szolwinski 1997].

In general, the transmission of load by friction is associated with concentration of the contact pressure. Contact will confine itself mainly close to the summits of the highest asperities. Therefore, the areas of real contact tend to be dispersed over the Hertzian area and these phenomena have an influence on a temporary value of friction load and the friction coefficient. In theoretical approach, the frictional force in sliding is proportional to normal load.

The comparison of a detailed actual graph of the friction coefficient and the theoretical one is presented in Fig. 5c and 5d. Theoretically, the friction coefficient is constant in sliding and its sign is changed when the ball specimen turns back. 
a)

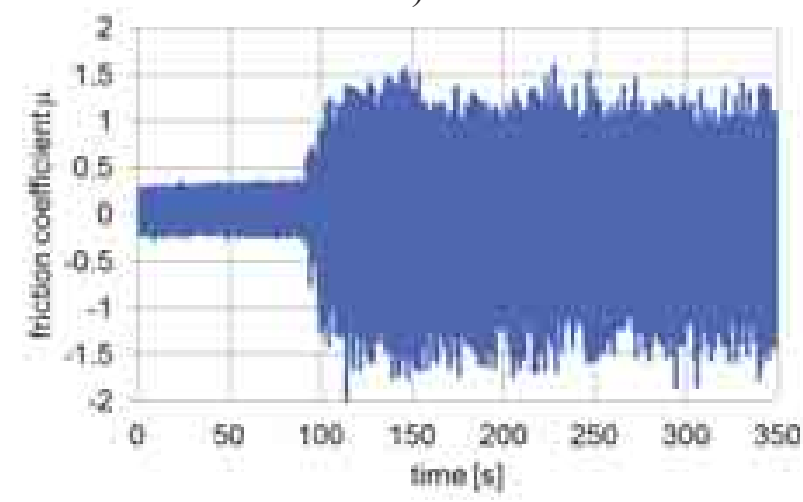

c)

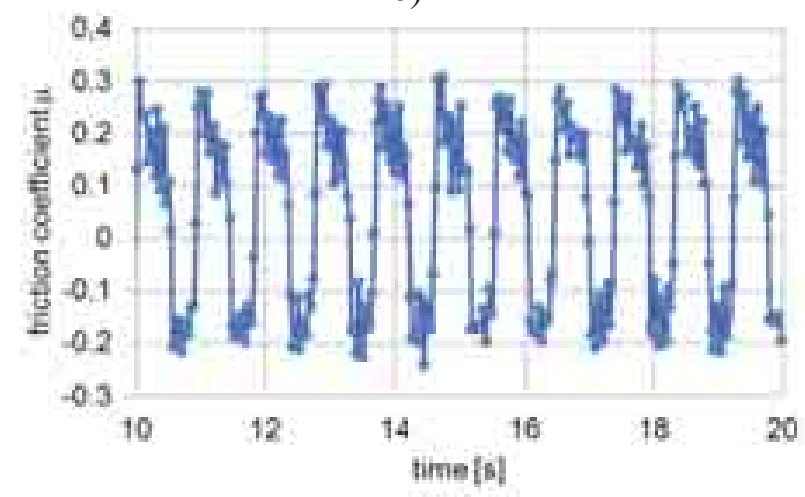

b)

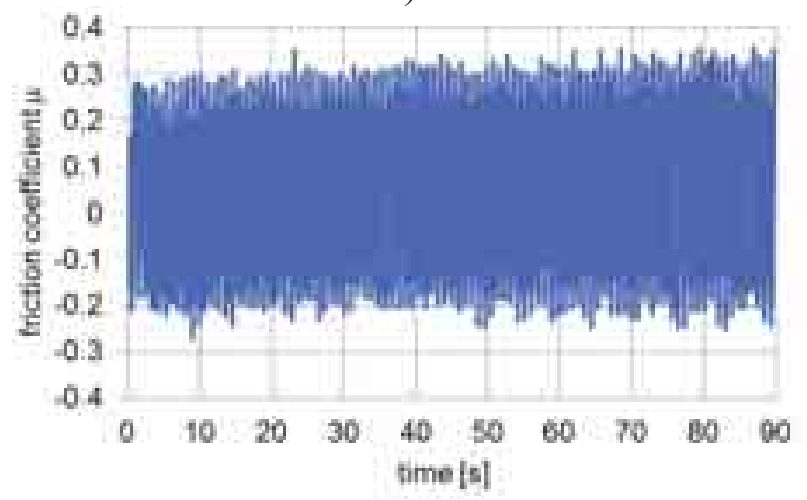

d)

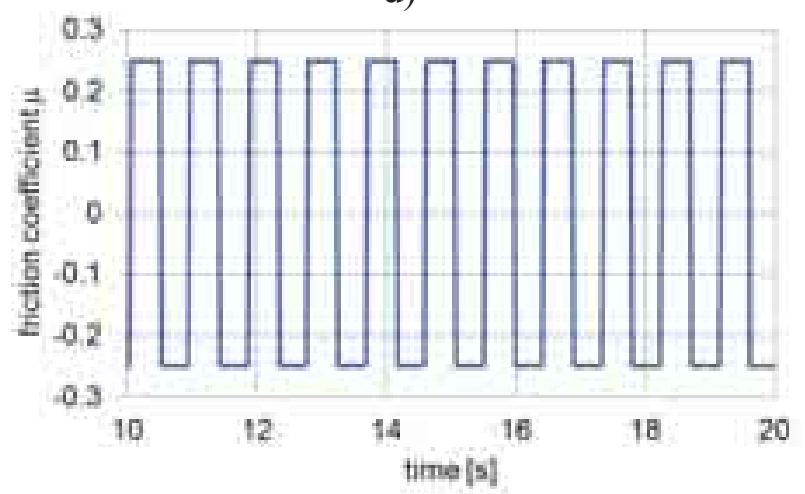

Fig. 5. Friction coefficient graph a) duration $350 \mathrm{~s}$ b) phase I-duration 90s c) duration - 10s d) hypothetical

\section{Estimation of friction coefficient}

Average and maximum values of the friction coefficient are determined on the base of temporary friction coefficient data in every test. The maximum value is calculated according to formula

$$
\mu_{\max }=\frac{1}{M} \sum_{k=1}^{M} \frac{\max _{j}\left(\mu_{j k}\right)-\min _{j}\left(\mu_{j k}\right)}{2},
$$

where $M$ - amount of cycles.

Graphs of temporary friction coefficients are fluctuated periodical functions and application of Fast Fourier Transform (FFT) algorithm seems to be an appropriate method to calculate an average coefficient value. Discrete Fourier Transform (DFT) is used in the analysis due to discrete representation of input data. DFT method transforms function $x$ defined in time domain into its frequency domain representation $X$ and corresponding amplitudes $a$

$$
\begin{gathered}
X(n)=\sum_{m=1}^{N} x(m) \cdot e^{\frac{2 \pi i}{N}(m-1)(n-1)}, \quad n=1 \ldots N, \\
a(n)=\frac{a b s(X(n))}{N}, \quad n=1 \ldots N,
\end{gathered}
$$

where $N$ - amount of points in all cycles, $i$ - imaginary unit.

The next step is the selection of maximum amplitude value $A=\max _{n}(a)$ which should correspond to test frequency $f$, setting all another $X$ components (of amplitude less than $A$ ) to zero ( $X_{1}$ is new $X$ representation) then use inverse DFT algorithm to compute sinusoidal function $x_{1}$ 


$$
x_{1}(m)=\frac{1}{N} \sum_{n=1}^{N} X_{1}(n) \cdot e^{\frac{2 \pi i}{N}(m-1)(n-1)}, \quad m=1 \ldots N .
$$

The average friction coefficient value is amplitude of $x_{1}$ and can be obtained with formula

$$
\mu_{\text {average }}=2 \cdot A \text {. }
$$

Sometimes maximum and minimum magnitudes/levels of the friction coefficient have different absolute values. In this case, $X$ value corresponding to zero frequency means the shift of the coefficient graph.

Magnitude $\mu_{\max }$ and $\mu_{\text {average }}$ can be treated as static (particularly during phase I) and dynamic friction coefficients, respectively.

Numerical calculations using DFT algorithm are performed with Matlab code. Typical friction coefficient graphs, original and after Fourier transformation, are presented in Fig. 6a and 6c, respectively. An Amplitude diagram versus frequency attained according to equation (3) is shown in Fig. $6 \mathrm{~b}$ and the maximum amplitude is marked/indicated in Fig. 6d.
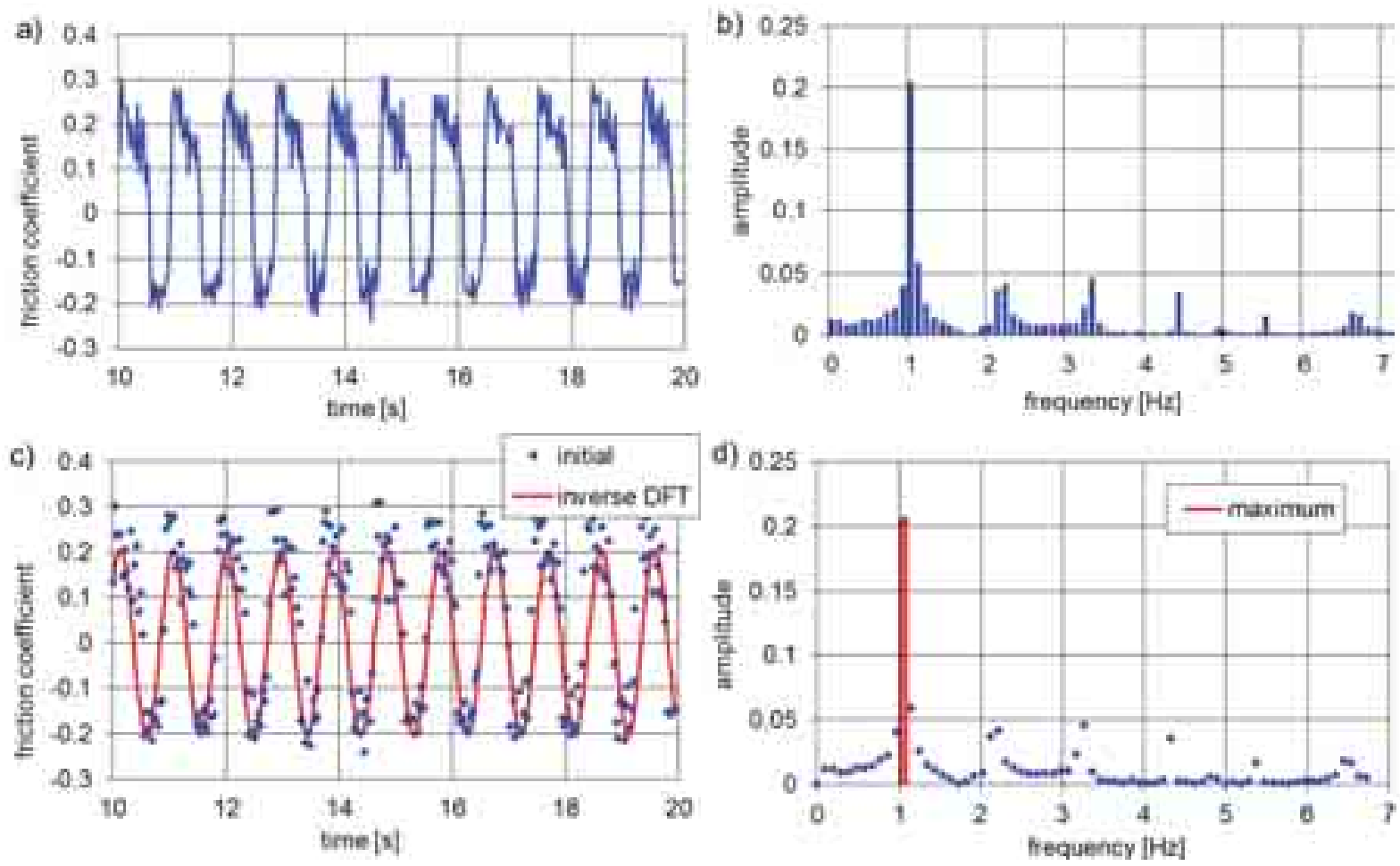

Fig. 6. Application of DFT algorithm to estimate dynamic friction coefficient

Maximum and average magnitudes of friction coefficients for bar and cladded flat specimens and for different normal load are compared in Tab. 2.

An increase of the friction coefficient with an increase of normal load is observed. A cladding layer also causes an increase of friction, especially in phase II. Phase I detected for normal load 10 $\mathrm{N}$ and $15 \mathrm{~N}$, contains only a few initial/early cycles so the friction coefficient is not calculated in those cases.

Fluctuation of experimental data in every test/attempt is estimated as difference between maximum and average value of the friction coefficient compared to its maximum value. The largest fluctuation reaching $60 \%$ is detected/observed for normal load $\mathrm{F}=5 \mathrm{~N}$. It can be an effect of surface damage and wear debris attendance/inherence connected with insufficient pressure in contact what may even cause temporary loss of contact. A growth of normal load causes a decrease of a fluctuation parameter to $30 \%-40 \%$. 
Tab. 2. Comparison of friction coefficients $\mu$

\begin{tabular}{|c|c|c|c|c|c|c|c|c|}
\hline $\begin{array}{l}\text { material/ } \\
\text { surface } \\
\text { condition }\end{array}$ & $\begin{array}{l}\text { applied } \\
\text { load [N] }\end{array}$ & $\begin{array}{c}\text { test } \\
\text { number }\end{array}$ & $\begin{array}{l}\text { phase I } \\
\mu_{\text {average }}\end{array}$ & $\begin{array}{c}\text { phase I } \\
\mu_{\max }\end{array}$ & $\begin{array}{l}\begin{array}{c}\text { fluctuation } \\
\mu_{\max }-\mu_{\text {average }} \\
\mu_{\max }\end{array}\end{array}$ & $\begin{array}{c}\text { phase II } \\
\mu_{\text {average }}\end{array}$ & $\begin{array}{c}\text { phase II } \\
\mu_{\max }\end{array}$ & $\begin{array}{l}\text { fluctuation } \\
\frac{\mu_{\max }-\mu_{\text {average }}}{\mu_{\max }}\end{array}$ \\
\hline \multirow{9}{*}{$\begin{array}{c}2024 \mathrm{~T} 3 \\
\text { bar }\end{array}$} & \multirow{4}{*}{$\mathrm{F}=5$} & $5 a$ & 0.07 & 0.23 & 0.70 & 0.23 & 0.51 & 0.55 \\
\hline & & $5 b$ & 0.05 & 0.20 & 0.75 & 0.21 & 0.42 & 0.50 \\
\hline & & $5 c$ & 0.08 & 0.19 & 0.58 & 0.25 & 0.45 & 0.44 \\
\hline & & $5 d$ & 0.07 & 0.16 & 0.56 & 0.07 & 0.17 & 0.59 \\
\hline & \multirow{4}{*}{$\mathrm{F}=10$} & $10 \mathrm{a}$ & 0.15 & 0.27 & 0.44 & 0.93 & 1.32 & 0.30 \\
\hline & & $10 \mathrm{~b}$ & 0.18 & 0.33 & 0.45 & 0.85 & 1.15 & 0.26 \\
\hline & & $10 \mathrm{c}$ & 0.13 & 0.21 & 0.38 & 0.82 & 1.45 & 0.43 \\
\hline & & $10 \mathrm{~d}$ & - & - & - & 0.72 & 1.05 & 0.31 \\
\hline & $F=15$ & $15 \mathrm{a}$ & - & - & - & 1.06 & 1.42 & 0.25 \\
\hline \multirow{9}{*}{$\begin{array}{l}\text { 2024T3 } \\
\text { cladded }\end{array}$} & \multirow{3}{*}{$\mathrm{F}=5$} & $5 a$ & 0.12 & 0.39 & 0.69 & 0.36 & 0.79 & 0.54 \\
\hline & & $5 b$ & 0.07 & 0.19 & 0.63 & 0.33 & 0.67 & 0.51 \\
\hline & & $5 c$ & 0.08 & 0.24 & 0.67 & 0.26 & 0.64 & 0.59 \\
\hline & \multirow{3}{*}{$\mathrm{F}=10$} & $10 \mathrm{a}$ & - & - & - & 0.99 & 1.67 & 0.41 \\
\hline & & $10 \mathrm{~b}$ & - & - & - & 1.09 & 1.70 & 0.36 \\
\hline & & $10 \mathrm{c}$ & - & - & - & 0.90 & 1.53 & 0.41 \\
\hline & \multirow{3}{*}{$\mathrm{F}=15$} & $15 \mathrm{a}$ & - & - & - & 0.98 & 1.58 & 0.38 \\
\hline & & $15 b$ & - & - & - & 1.12 & 1.69 & 0.34 \\
\hline & & $15 \mathrm{c}$ & - & - & - & 1.28 & 1.97 & 0.35 \\
\hline
\end{tabular}

\section{Conclusions}

The results of ball on flat tests for aluminium alloy bar and cladded specimens and estimation of the friction coefficient are presented in the paper.

Specimen surface after wear testing is analysed using SEM. The surface of a cladded sample tends to become more degraded and wear track width is greater than in the case of a bar one.

Frictional force is recoded during the test and the temporary friction coefficient is calculated. Static and dynamic (kinetic) coefficients are estimated as maximum and average amplitude of friction graph, respectively. The average (dynamic) friction coefficient is calculated using DFT algorithm and frequency representation of the friction graph.

Friction coefficient value depends on the specimen surface and applied load. Greater values (about 0.1 ) are obtained for cladded samples. The increase in applied load causes a growth of wear and friction coefficient.

\section{References}

[1] Stolarski, T. A., Tribology in machine design, Butterworth-Heinemann Oxford 1990/2000

[2] Popov, V. L., Contact Mechanics and Friction, Physical Principles and Applications, Springer-Verlag 2010. 
[3] Endo, H., Marui, E., Effect of reciprocating and unidirectional sliding motion on the friction and wear of copper on steel, Wear 249, pp. 582-591, 2001.

[4] Jachimowicz, J., Kaniowski, J., Szymczyk, E., Kozłowski, P., Moneta, G., Zjawisko frettingu w konstrukcjach lotniczych, Transaction of ILOT, 206, 4, pp. 36-38, 2010.

[5] Zmitrowicz, A., Wear patterns and laws of wear - a review, Journal of theoretical and applied mechanics 44, pp. 219-253, Warsaw 2006.

[6] Müller, R., An experimental and numerical investigation on the fatigue behaviour of fuselage riveted lap joints, Doctoral Dissertation, Delft University of Technology, 1995.

[7] Szolwinski, M. P., The mechanics and tribology of fretting fatigue with application to riveted lap joints, West Layfayette, IN, USA Purdue University, USA 1998.

[8] Metals Handbook, Vol. 18, ASM, 8th Editions, 1992. 